\title{
Compatibilidade em cruzamentos intra e interespecíficos em pimenteiras ornamentais ${ }^{\left({ }^{\prime}\right)}$
}

\author{
NAYSA FLÁVIA F. DO NASCIMENTO(2,3); ELIZANILDA RAMALHO DO RÊGO(2,4,6); \\ MAILSON MONTEIRO DO RÊGO(2,4,5); MAYANA F. NASCIMENTO(2,3); LÂNIA ÍSIS F. ALVES ${ }^{(2,5)}$
}

\section{RESUMO}

\begin{abstract}
A hibridação é importante na evolução das plantas como fonte de novas combinações genéticas e como mecanismo de especiação. O objetivo deste trabalho foi avaliar a compatibilidade de cruzamentos em espécies do gênero Capsicum. Para tanto, foram realizados cruzamentos dialélicos entre os genitores Capsicum annuum (UFPB 01, UFPB 77.1, UFPB 77.2, UFPB 132, UFPB 134 e UFPB 137), C. baccatum (UFPB 72) e C. chinense (UFPB 128) pertencentes ao Banco de Germoplasma da CCA-UFPB. Os cruzamentos interespecíficos entre estas espécies que mostraram-se promissores, produzindo frutos e bom número de sementes, foram C. annuum. x C. baccatum: UFPB 01 x UFPB 72, UFPB 134 x UFPB 72, UFPB 77.1 x UFPB72, UFPB 137 x UFPB 72, UFPB 77.2 x UFPB 72. Os cruzamentos recíprocos entre as espécies de $C$. baccatum x C. annuum (UFPB 72 x UFPB 01 e UFPB 01 x UFPB $72=53 \%$ ) foram os que apresentaram maior pegamento de frutos. A combinação entre C. baccatum x C. chinense não foi compatível, já o recíproco C. baccatum x $C$. chinense mostrou $50 \%$ de porcentagem de pegamento.

Palavras-chave: pimenta, melhoramento, hibridação genética, Capsicum.
\end{abstract}

\section{ABSTRACT}

Compatibility and reciprocal effect in intra and interspecific crosses of ornamental pepper

The hybridization is important to plant evolution providing new genetic combination and to promote speciation. The goal of this work was to evaluate the cross compatibility in Capsicum genus. For this diallel were used eight parents belonging to the Germplasm Bank of Centro de Ciências Agrárias/Universidade Federal da Paraíba. These parents were Capsicum annuит (UFPB 01, UFPB 77.1, UFPB 77.2, UFPB 132, UFPB 134 e UFPB 137), C. baccatum (UFPB 72) C. chinense (UFPB 128). The interspecific crosses that showed high percentages of fruits and seeds were C. annuum $\mathrm{x}$ C. baccatum: UFPB 01 x UFPB 72, UFPB 134 x UFPB 72, UFPB77.1 x UFPB72, UFPB 137 x UFPB 72 and UFPB 77.2 x UFPB 72. The reciprocal crosses between C. baccatum x C. annuum (UFPB 72 x UFPB 01 e UFPB $01 \times$ UFPB $72=53 \%$ ) showed high fruit set. There was no compatibility between $C$. baccatum x $C$. chinense but their reciprocal cross $C$. chinense $\mathrm{x}$. baccatum showed $50 \%$ of fruit set.

Keywords: chilli, pepper breeding, hybridization, genetics, Capsicum.

\section{INTRODUÇÃO}

O gênero Capsicum é de origem americana, pertence à família Solanaceae e é composto de cerca de 35 táxons (espécies e suas variedades). As espécies podem ser classificadas de acordo com o nível de domesticação, de modo que o gênero é constituído por cinco táxons domesticados, entre eles estão $C$. annuиm, $C$. chinense e $C$. baccatum, sendo cerca de dez semidomesticados e cerca de 20 silvestres (BIANCHETTI e CARVALHO, 2005).

As pimentas do gênero Capsicum estão intimamente relacionadas à riqueza cultural brasileira e são parte valiosa do patrimônio da biodiversidade, sendo cultivadas em uma imensa variedade de tipos, tamanhos, cores, sabores e pungências (NEITZKE et al., 2008).

As espécies de Capsicum apresentam flores perfeitas e se reproduzem preferencialmente por autofecundação espontânea (BOSLAND, 1996). Estudos têm mostrado que a polinização cruzada pode ocorrer em uma faixa de
2 a $90 \%$, estando esse cruzamento associado à presença de insetos polinizadores (BOSLAND e VOTAVA, 1999; NASCIMENTO et al., 2006).

A hibridação interespecífica é muito importante como fonte de novas combinações genéticas e como mecanismo de especiação, sendo útil no cultivo de plantas para transferência de genes de interesse agronômico, como os de resistência a doenças e a insetos (JUDD et al., 2009; STUMMEL e BOSLAND, 2006).

No mercado de pimenteiras ornamentais, a cor do fruto e a arquitetura da planta são características de grande importância, preferindo-se plantas baixas e fruto colorido e ereto, além de resistência a doenças e pragas e a estresse abiótico (POULOS, 1994, RÊGO et al., 2009a). Para o uso eficiente dos recursos genéticos nos programas de melhoramento de plantas, é necessário o conhecimento detalhado da extensão e distribuição da variação genética disponível nas espécies cultivadas e seus parentes silvestres (BUSO et al., 2003; RÊGO, et al., 2006).

\footnotetext{
(1) Recebido em 13/10/2009 e aceito para publicação em 16/11/2011.

(2) Laboratório de Biotecnologia Vegetal - Centro de Ciências Agrárias - Universidade Federal da Paraíba, 58397-000, Areia - PB; e-mail: elizanilda@ cca.ufpb.br

(3) Bolsista IC-CNPq.

(4) Professor Adjunto do Centro de Ciências Agrárias da Universidade Federal da Paraíba - UFPB.

${ }^{(5)}$ Bolsista em extensão no país - CNPq.

(6) Bolsista de Produtividade em Pesquisa-CNPq.
} 
Em Capsicum, são poucos os registros de hibridização interespecífica em programas de melhoramento, apesar de algumas espécies apresentarem características interessantes para produção de plantas de interesse comercial. O objetivo desse trabalho foi avaliar a compatibilidade de cruzamentos em espécies ornamentais do gênero Capsicum pertencentes ao Banco de Germoplasma de Hortaliças do CCA/UFPB.

\section{MATERIAL E MÉTODOS}

O experimento foi realizado de junho de 2008 a fevereiro de 2009. As sementes foram semeadas em bandeja de poliestireno expandido com 128 células, utilizandose substrato comercial Plantmax ${ }^{\mathrm{R}}$. O transplante se deu quando as plantas apresentavam quatro folhas definitivas. As plantas foram cultivadas em vaso plástico de $900 \mathrm{~mL}$ utilizando-se o mesmo substrato e conduzidas em casa de vegetação no setor de Biotecnologia do Centro de Ciências Agrárias - Universidade Federal da Paraíba (CCA-UFPB).

Foram utilizados oito genitores pertencentes à coleção de germoplasma da CCA-UFPB: C. annuum (UFPB 01, UFPB 77.1, UFPB 77.2, UFPB 132, UFPB 134 e UFPB 137), C. baccatum (UFPB 72) e $C$. chinense (UFPB 128). Foram realizados todos os cruzamentos e seus recíprocos, em esquema dialélico, gerando 56 combinações híbridas. Os cruzamentos foram manuais e realizados em botões florais emasculados antes da antese (Figuras 1A e 1B). Foram realizados pelo menos nove cruzamentos para cada combinação híbrida, em função da disponibilidade de flores. Imediatamente após a emasculação, as flores foram polinizadas por meio da condução do pólen de uma planta para o estigma da flor receptora (Figuras 1C e 1D). Após a polinização, a flor foi coberta com papel alumínio para evitar contaminação (Figura 1E) e etiquetada (Figura 1F).

A coleta do fruto maduro foi realizada, em média, de um a dois meses após a polinização, variando de acordo com as espécies. A porcentagem de pegamento de frutos foi dada pelo número de frutos formados pelo total de cruzamentos feitos. Após a colheita dos frutos, foi feita a contagem do número de sementes por fruto. Em seguida, as sementes foram secadas em estufa a $37^{\circ} \mathrm{C}$ com ventilação forçada até obtenção de peso constante e, a seguir, armazenadas em câmara fria. No estudo de cruzamentos recíprocos, foram utilizados 28 híbridos e seus recíprocos, provenientes do cruzamento dialélico de oito acessos do Banco de Germoplasma de Hortaliças da Universidade Federal de Viçosa. As médias referentes às características avaliadas nos híbridos e seus recíprocos foram comparadas utilizando-se o teste t. A expressão utilizada na comparação das médias de qualquer híbrido e seu recíproco foi:

Em que: $\quad \mathrm{t}=\frac{\hat{Y} \boldsymbol{j}-\hat{Y} \boldsymbol{j}}{\sqrt{\frac{s}{n}}}$

$\hat{Y}_{i j}$ é a média do híbrido $\mathrm{F}_{1}$, obtida do cruzamento entre a fêmea i e o macho j; $\hat{Y}_{j i}$, a média do híbrido recíproco, obtida do cruzamento entre fêmea $\mathrm{j}$ e do macho $\mathrm{i} ; \mathrm{n}$, o número de observações que deram origem às médias dos híbridos; e s é o desvio padrão da característica.

Para a análise estatística dos dados, utilizou-se o programa GENES (CRUZ, 2001).

\section{RESULTADOS E DISCUSSÃO}

As combinações que apresentaram maior porcentagem de formação de frutos e com maior número de sementes foram as intraespecíficas entre acessos de $C$. annuum (UFPB 01 X UFPB $77.2=100 \%$, UFPB 134 X UFPB $77.2=100$, UFPB 01 X UFPB $132=91 \%$, UFPB $77.1 \mathrm{X}$ UFPB $137=75 \%$ E $̋ 01 \mathrm{X}$ ○ $77.1=70 \%$ ). Considerável incompatibilidade entre cruzamentos intraespecíficos foi observada entre acessos de C. annuum (UFPB $77.2 \mathrm{x}$ UFPB $01=17 \%$ ) (Tabela 01$)$.

A compatibilidade intraespecífica variou tanto com a direção dos cruzamentos como com o a linhagem utilizada no cruzamento. Estes dados mostram a importância do conhecimento da compatibilidade de cruzamentos entre os genitores que se pretende utilizar em programas de melhoramento, como preconizado por RÊGO et al. (2009b).

Entre os cruzamentos interespecíficos, o pegamento de fruto variou para os cruzamentos $C$. baccatum $x$ C. annuum (UFPB 72 x UFPB $137=100 \%$, UFPB 72 x UFPB $134=80$ $\%$, UFPB 72 x UFPB $01=71 \%$ ) e $C$ chinense $x$ C.annuum (UFPB 128 x UFPB $77.2=100 \%$ ). Os cruzamentos interespecíficos entre essas espécies que mostraram-se promissores produzindo frutos e bom número de sementes foram $C$. annuum $x$ C. baccatum (UFPB $01 \times$ UFPB 72 , UFPB 134 x UFPB 72, UFPB 77.1 x UFPB 72, UFPB 137 x UFPB 72 e UFPB 77.2 x 72). Os dados encontrados neste trabalho confirmam aqueles citados por STUMMEL e BOSLAND (2006), que relataram diferentes níveis de pegamento em cruzamentos interespecíficos em pimenteira ornamental. Ainda conforme estes autores, os cruzamentos entre as espécies de $C$. chinense e $C$. annuum são de interesse no melhoramento de pimenteiras ornamentais para transferência de genes de resistência a vírus.

A combinação entre as espécies de C. baccatum $\mathrm{x}$ C. chinense não foi compatível, tendo apresentado $0 \%$ de pegamento de frutos. Já o recíproco $C$. chinense x C. baccatum apresentou $50 \%$ na porcentagem de pegamento. Estes dados discordam daqueles encontrados por PICKERGILL (1980), que mostrou terem sido essas espécies compatíveis em cruzamentos recíprocos.

Houve variação na porcentagem de pegamento de frutos de 0 a $29 \%$, entre C. annuum e C. chinense, discordando dos dados obtidos por LANTERI e PICKERSGILL (1993), que encontraram incompatibilidade, com $0 \%$ de pegamento nos cruzamentos entre estas espécies.

Observou-se que o pegamento é dependente do background do acesso da espécie de $C$. annuum utilizada, como pode ser observado nos cruzamentos com baixo índice de pegamento entre Chinense $x$ C. annuum (UFPB $128 \times$ UFPB $01,=10 \%), C$. annuum $\times$ C. chinense (UFPB $137 \times$ UFPB $128=10 \%$, UFPB $128 \times$ UFPB $137=29 \%$, UFPB $132 \times$ UFPB $128=0 \%$, UFPB $128 \times$ UFPB $132=$ $14 \%$ ) e $C$. annuum $x$ C. chinense (UFPB $128 \times$ UFPB 01 $=10 \%$, UFPB $01 \times$ UFPB $128=14 \%$ ), com baixo número de sementes formadas. Dados semelhantes foram obtidos 
por COSTA et al. (2009) trabalhando com diferentes acessos de $C$. chinense em cruzamento com $C$. annuum, com percentagens de pegamento variando de 8,88 a $40 \%$, dependendo do acesso utilizado.

Foram detectados efeitos recíprocos nas características avaliadas, e os genitores apresentaram diferenças significativas em mais de $50 \%$ de seus cruzamentos, verificando-se, assim, a importância desses efeitos nesses caracteres (Tabela 1). É válido salientar que os efeitos recíprocos podem afetar caracteres de fruto e planta como relatado por RÊGO et al. (2009b) em C. baccatum.

\section{AGRADECIMENTOS}

Os autores são gratos ao CNPq pelo auxílio financeiro, processos $n^{\circ} 551524 / 2007-3$ e $n^{\circ} 474988 / 20082$, e pela concessão de bolsas aos autores.

\section{REFERÊNCIAS}

BIANCHETTI, L.; CARVAlHO, S. I. C. Subsídios à coleta de germoplasma de pimentas e pimentões do gênero Capsicum (Solanaceae). In: WALTER, B.M.T; CAVALCANTI, T.B. Fundamentos para coleta de germoplasma vegetal. Brasília: Embrapa Recursos Genéticos e Biotecnologia, 2005, p.355-385.

BOSLAND, P.W. Capsicums: innovative uses of an ancient crop. In: JANICK, J. (Ed.). Progress in new crops. Arlington: ASHS Press, 1996, p.479-487.

BOSLAND, P.W.; VOTAVA, E.J. Peppers: vegetable and spice capsicums. Wallingford: Cabi, 1999. 204p.

BUSO, G.S.C.; AMARAL, Z.P.S.; MACHAD, F.R.B.; BEM, L.B.; FERREIRA ME. Variedade Genética e Análise Filogenética de Espécies Brasileiras de Pimenta e Pimentão (Capsicum spp). In: Congresso Brasileiro De Melhoramento de Plantas, 2, 2003. Anais... Porto Seguro: SBMP 1 CD-ROM.

COSTA, L.V., LOPES,R. LOPES, M.T. FIGUEREDO, A. F., BARROS, W.S. ALVES, S.R.M. Cross compatibility of domesticated hot pepper and cultivated sweet pepper. Crop Breeding and Applied Biotechnology. Minas Gerais: UFV, 2009. v.9, p.181-186,

CRUZ CD. Programa Genes (versão Windows): aplicativo computacional em genética e estatística. Viçosa:
UFV, 2001. 648p.

JUDD, W. S.; CAMPBELL, C. S.; KELlOGG, E. A.; STEVENS, P. F.; DONOGHUE, M. J. Sistemática Vegetal. Um enfoque filogenético. 3.ed. Porto Alegre: Artmed, 2009. 632p.

LANTERI, S. PICKERSGILL, B. Chromosomal structural changes in Capsicum annuum L. and C. chinense Jack.. CAB Abstracts, p.10-24, 1993.

NASCIMENTO, W.M. et al. Produção de sementes de pimentas. Informe Agropecuário, Belo Horizonte, v.27, p.30-39, 2006.

NEITZKE, R. S.; BARBIERI, R. L.; HEIDEN, G.; CASTRO, C. M. Divergência genética entre variedades locais de Capsicum baccatum utilizando caracteres multicategóricos. Magistra, Cruz das Almas-BA, v.20, n.3, p.249-255, 2008.

PICKERGILL, B. Some aspects of interespecific hybridization in Capsicum. IVth Meeting of the EUCARPIA Capsicum Working Group, p.14-16, 1980.

POULOS, J.M. Pepper Breeding (Capsicum spp.): achievements, challenges and possibilities. Plant Breeding Abstracts, v.64, n.2, p.144-155, 1994.

RÊGO, E. R.; FINGER, F.L; CRUZ, C. D. e RÊGO, M.M. Caracterização, diversidade e estimação de parâmetros genéticos em pimenteiras (Capsicum spp.). In: Encontro Nacional do Agronegócio Pimentas (Capsicum spp.), 2, 2006. Anais.

REGO, E. R. ; RÊGO, M. M. ; SILVA, D. F. ; CORTEZ, R. M. ; SAPUCAY, M. J. L. C. ; SILVA, D. R. ; SILVA JUNIOR, S. J. Selection for leaf and plant size and longevity of ornamental peppers (Capsicum spp.) grown in greenhouse condition. Acta Horticulturae, Bélgica, v. 829, p.371-375, 2009a.

RÊGO, E. R. ; REGO, M. M. ; FINGER, F. L. ; CRUZ, C. D. ; CASALI, V. W. D.. A diallel study of yield components and fruit quality in chilli pepper (Capsicum baccatum). Euphytica, Wageningen, v. 168, p. 275-287, 2009 b.

STUMMEL, JR; BOSLAND, P. Ornamental pepper. Capsicum annuum. In: ANDERSON, N.O. Flower breeding and genetics: issues, challenges, and opportunities for the 21 st Century, ed. Dordrecht, Holanda: Springer, 2006. p.561-599, 
Tabela 1. Porcentagem de frutos formados e número de sementes por fruto em cruzamentos intra e interespecíficos em Capsicum spp

Table 1. Percentage of beared fruits and number of fruits per interspecific cross in Capsicum spp

\begin{tabular}{|c|c|c|c|c|c|}
\hline Híbridos & $\begin{array}{c}\text { Frutos por } \\
\text { Cruzamento }(\%)\end{array}$ & $\begin{array}{l}\text { Número de } \\
\text { sementes }\end{array}$ & Híbridos & $\begin{array}{c}\text { Frutos por } \\
\text { Cruzamento }(\%)\end{array}$ & $\begin{array}{l}\text { Número de } \\
\text { sementes }\end{array}$ \\
\hline Hybrids & $\begin{array}{l}\text { Fruits per cross } \\
(\%)\end{array}$ & Number of seeds & Hybrids & Fruits per cross & Number of seeds \\
\hline $72 \times 01$ & $71 * *$ & $7 * *$ & $128 \times 77.1$ & $20 \mathrm{~ns}$ & Ons \\
\hline $01 \times 72$ & 53 & 35 & $77.1 \times 128$ & 20 & 0 \\
\hline $77.1 \times 01$ & $70 * *$ & $26 \mathrm{~ns}$ & $132 \times 77.1$ & $29 * *$ & $31 * *$ \\
\hline $01 \times 77.1$ & 50 & 24 & $77.1 \times 132$ & 47 & 18 \\
\hline $77.2 \times 01$ & $17 * *$ & $19 * *$ & $134 \times 77.1$ & $67 \mathrm{~ns}$ & $11 \mathrm{~ns}$ \\
\hline $01 \times 77.2$ & 100 & 31 & $77.1 \times 134$ & 67 & 13 \\
\hline $128 \times 01$ & $10 \mathrm{~ns}$ & $41 * *$ & $137 \times 77.1$ & $40 * *$ & $45^{* *}$ \\
\hline $01 \times 128$ & 14 & 5 & $77.1 \times 137$ & 75 & 31 \\
\hline $132 \times 01$ & $63 * *$ & $20 * *$ & $128 \times 77.2$ & $100 * *$ & $49 * *$ \\
\hline $01 \times 132$ & 91 & 9 & $77.2 \times 128$ & 43 & 0 \\
\hline $134 \times 01$ & $36 * *$ & $33 \mathrm{~ns}$ & $132 \times 77.2$ & $61 * *$ & $21 \mathrm{~ns}$ \\
\hline $01 \times 134$ & 60 & 26 & $77.2 \times 132$ & 45 & 24 \\
\hline $137 \times 01$ & $50 * *$ & $26 \mathrm{~ns}$ & $134 \times 77.2$ & $100 * *$ & $43 * *$ \\
\hline $01 \times 137$ & 33 & 31 & $77.2 \times 134$ & 27 & 24 \\
\hline $77.1 \times 72$ & $53 \mathrm{~ns}$ & $25 * *$ & $137 \times 77.2$ & $22 * *$ & $39 * *$ \\
\hline $72 \times 77.1$ & 45 & 9 & $77.2 \times 137$ & 50 & 23 \\
\hline $77.2 \times 72$ & $77 * *$ & $14 \mathrm{~ns}$ & $132 \times 128$ & $0^{*}$ & Ons \\
\hline $72 \times 77.2$ & 40 & 12 & $128 \times 132$ & 14 & 0 \\
\hline $128 \times 72$ & $50 * *$ & $50 * *$ & $134 \times 128$ & $46^{*}$ & $6 \mathrm{~ns}$ \\
\hline $72 \times 128$ & 0 & 0 & $128 \times 134$ & 33 & 5 \\
\hline $132 \times 72$ & $40 \mathrm{~ns}$ & $13 \mathrm{~ns}$ & $137 \times 128$ & $10 * *$ & $0 * *$ \\
\hline $72 \times 132$ & 35 & 20 & $128 \times 137$ & 29 & 16 \\
\hline $134 \times 72$ & $50 * *$ & $42 * *$ & $134 \times 132$ & $65^{*}$ & $40 * *$ \\
\hline $72 \times 134$ & 80 & 18 & $132 \times 134$ & 50 & 17 \\
\hline $137 \times 72$ & $36 * *$ & $47 * *$ & $137 \times 132$ & $52 \mathrm{~ns}$ & $43 * *$ \\
\hline $72 \times 137$ & 100 & 12 & $132 \times 137$ & 63 & 24 \\
\hline $77.2 \times 77.1$ & $59 * *$ & $22 \mathrm{~ns}$ & $137 \times 134$ & $52 \mathrm{~ns}$ & $33 \mathrm{~ns}$ \\
\hline $77.1 \times 77.2$ & 30 & 26 & $134 \times 137$ & 55 & 33 \\
\hline
\end{tabular}

ns, * $\mathrm{e}^{* *}$, não significativo, significativo a 5 e $1 \%$, respectivamente, pelo teste t.

$n s, *$ and $* *$ not significant, significant at 5 and $1 \%$, respectively, by $t$ test. 

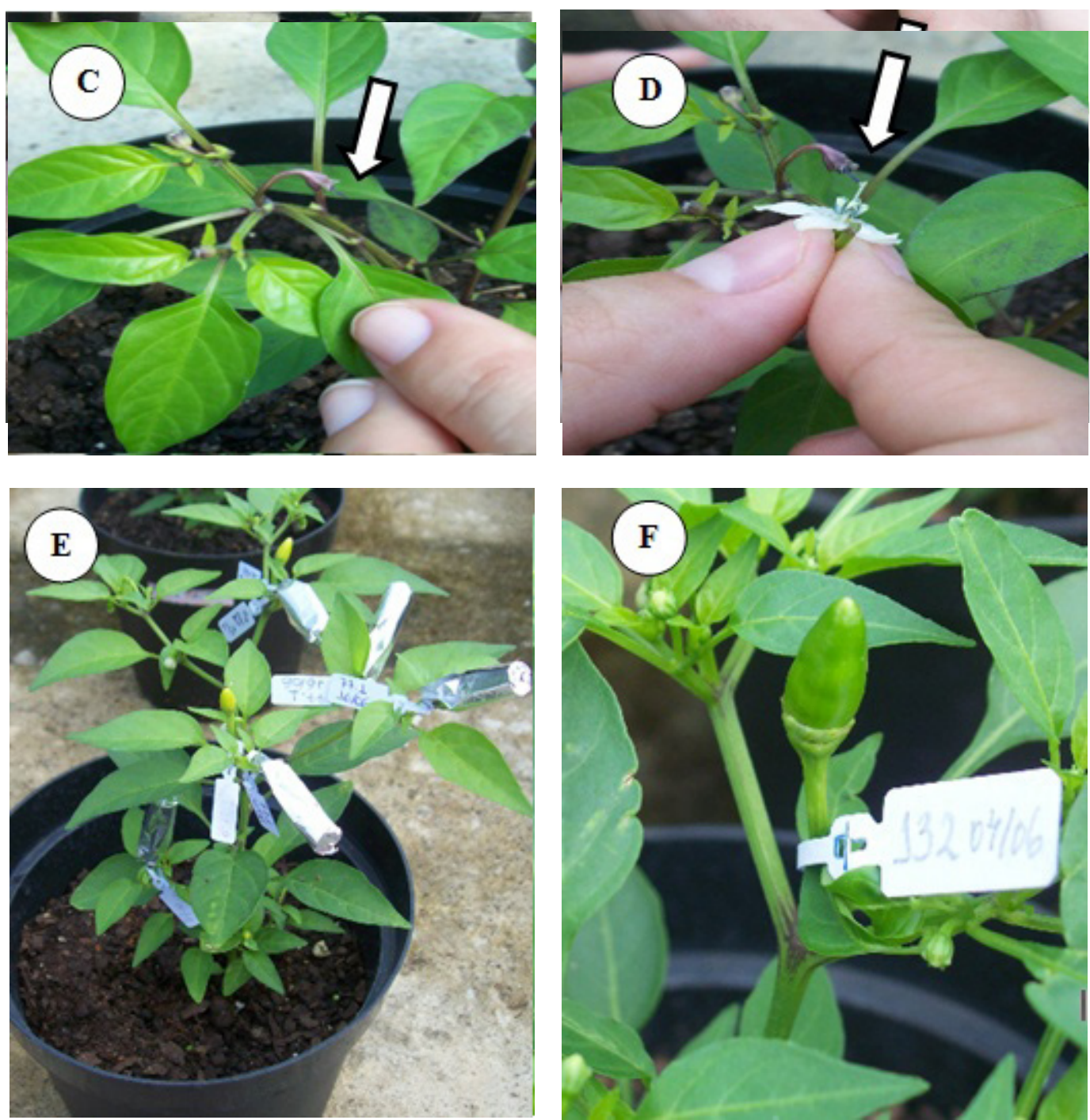

Figura 1. Procedimento para polinização cruzada em Capsicum annuum. Etapas do cruzamento - (A, B) Emasculação. (C) Botão emasculado. (D) Polinização. (E) Botão coberto. (F) Fruto imaturo marcado.

Figure 1. Procedure of flower pollination on Capsicum annuum and fruit set: flower bud before emasculation - (A, B) Emasculation. (C) Emasculated flower bud. (D) Pollination. (E) Bud protection after pollination. (F) Immature marked fruit. 